\title{
Photocatalytic properties for different metal-oxide nanomaterials
}

Rania E. Adam, Elfatih Mustafa, S. Elhag, O. Nur, M. Willander

Rania E. Adam, Elfatih Mustafa, S. Elhag, O. Nur, M. Willander, "Photocatalytic properties for different metal-oxide nanomaterials," Proc. SPIE 10919, Oxide-based Materials and Devices X, 1091925 (1 March 2019); doi: 10.1117/12.2517436

SPIE. Event: SPIE OPTO, 2019, San Francisco, California, United States 


\title{
Photocatalytic properties for different metal-oxide nanomaterials
}

\author{
Rania E. Adam, Elfatih Mustafa, S. Elhag, O. Nur, M. Willander* \\ Department of Science and Technology, Campus Norrköping, Linköping University, SE-601 74 \\ Norrköping, Sweden
}

\begin{abstract}
We here demonstrate the synthesis of different nanostructures, including nanoparticles, nanorods, core-shell structures, and compound metal oxide nanostructures all synthesized by a low temperature chemical process. We further investigated their photocatalytic properties for degradation of toxic waste and their photochemical efficiency for water splitting. All the photocatalytic properties as well as the photochemical properties were utilized using sun radiation. The results presented indicate huge potential for the investigated processes with positive impact to energy consumption and benefits for the environment.
\end{abstract}

Keywords: Single nanostructures, compound nanostructures, core-shell structures, photocatalytic degradation, Solar driven photocatalysis

\section{INTRODUCTION}

Photocatalysis activities of semiconductors such as dyes photodegradation, hydrogen production via photoelectrochemical water oxidation have been studies, due to their positive impact to the environment and energy availability issues [1-4]. These semiconductors include $\mathrm{WO}_{3}, \mathrm{TiO}_{2}, \mathrm{Fe}_{2} \mathrm{O}_{3}, \mathrm{BiVO}_{4}$, and $\mathrm{ZnO}$ [5-10]. From above mentioned semiconductors, $\mathrm{ZnO}$ has a wide band gap $(\mathrm{Eg} \sim 3.3 \mathrm{eV})$, and relatively high carriers' mobility $[8,11,12]$. However, the high recombination rate of photo-generated charge carriers is the most influential factor that limits the efficiency of the photocatalytic processes of the $\mathrm{ZnO}[1,13-16]$. To tackle this obstacle, and to increase the photocatalytic activities of the $\mathrm{ZnO}$ under visible solar light, variety of studies are conducted to increase the photocatalytic response of the $\mathrm{ZnO}$ through doping with metals (e.g. Ag, and $\mathrm{Pb}$. etc) and transition metals (e.g. $\mathrm{Mn}$, and Co) [17] or through coupling with other semiconductors or photosensitizer to form an efficient heterostructure material $[13,14,16]$. Magnesium $(\mathrm{Mg})$ is a promising metal for doping $\mathrm{ZnO}$ and then can improve the photocatalytic activities of ZnO NPs under solar radiation and can be used for decomposition of organic dyes into less toxic compounds $[18,19]$. Herein, we report an efficient photocatalytic activity of $\mathrm{ZnO} \mathrm{NP}$ doped with $\mathrm{Mg}$ under illumination of solar light. The NPs were grown through the low temperature $\left(\sim 60^{\circ} \mathrm{C}\right)$ co-precipitation method. We studied the photocatalytic activities of the $\mathrm{ZnO}$ nanoparticles (NPs) and Mg-doped ZnO NPs for degradation of methylene blue (MB). We show the photodegradation efficiency of MB using the pure and Mg-doped ZnO NPs. In addition, Ag-based compounds are regarded as an excellent candidate as a co-catalyst that can largely enhance solar energy conversion efficiency and

\footnotetext{
*magnus.willander@liu.se;
}

Oxide-based Materials and Devices X, edited by David J. Rogers, David C. Look, Ferechteh H. Teherani, Proc. of SPIE Vol. 10919, 1091925 - @ 2019 SPIE

CCC code: $0277-786 X / 19 / \$ 18 \cdot$ doi: $10.1117 / 12.2517436$ 
charge separation, which lead to further boost the PEC performance. Recent studies have proven that the deposition of Ag-containing species on the surface of composites, can lead to effectively improve harvesting visible light and increase the photo-generated charge carriers separation owing to the surface plasmon resonance (SPR) effect $[13,14,16]$. The net result will be an enhanced PEC activity of the Ag containing composites. In this regard, silver tungsten (Ag2WO4) with a band gap between 2.9-3.1 eV, have been used for preparation of different outstanding plasmonic photo-catalysts [14,20-22]. Accordingly, we report the synthesis, characterization, and PEC activities of Ag/Ag2WO4 grown on top of $\mathrm{ZnO}$ nanorods (NRs). Firstly, $\mathrm{ZnO} \mathrm{NRs}$ is synthesized using the hydrothermal low temperature chemical method. This was followed by the $\mathrm{Ag} / \mathrm{Ag} 2 \mathrm{WO} 4$ deposition on top of the $\mathrm{ZnO}$ NRs using the SILAR method. The results showed an enhancement on the photocurrent and the current-voltage measurements, which are promising results for water splitting application

On the other hand, water contamination due to non-biodegradable organic dyes from industrial waste is a very serious environmental hazard. Pollutants that are emitted from various sources pose severe ecological problem. Therefore, removal of these dyes from industrial wastewater is highly desirable. All existing protocols for the treatment of wastewater are categorized as physical, chemical or biological processes. However, most of these treatments have intricacy in realistic uses. Biological processes, as an example, have been extensively used and show potential towards dairy and agricultural wastewater treatment. These processes have limitations, which can potentially affect degradation efficiency through control $\mathrm{pH}$ range, rapid organic-load variations, and the effluents physicochemical behavior. Among the chemical process, the advanced oxidation processes (AOP), is a heterogeneous photocatalysis that deals with photocatalysts like $\mathrm{TiO}_{2}, \mathrm{ZnO}$ are the most studied photocatalysts mediated degradation of the industrial wastewater, appears as an emerging technology leading to the total mineralization of most of the organic pollutants. However, it has a drawback that it can operate only under ultraviolet light due to the band gap limitations. Furthermore, this method could be a more expensive when it is scaled-up because particle-recovery of the photocatalyst particles is a difficult task and leads to an amplification in process costs. In this connection, and to develop a system for heterogeneous photocatalytic treatment of organic dyes in aqueous media under solar light irradiation, it is a key task to exploit photocatalysts with high stability (recycled), high efficiency, low recombination rate of negatively charged electrons and positive holes, and with low cost. One of the most advanced artificial photocatalysis material candidate is $\mathrm{BiM}_{2} \mathrm{AO}_{6}$ (with $\mathrm{M}: \mathrm{Mg}, \mathrm{Ca}, \mathrm{Cd}, \mathrm{Cu}, \mathrm{Pb}, \mathrm{Mn}$ or $\mathrm{Zn}$, and $\mathrm{A}: \mathrm{V}, \mathrm{P}$ or As) so called mixed metal oxide (MMO) semiconductors have great potential to be used as photocatalysts. However, so far only a few candidates of this family have been investigated, namely $\mathrm{BiCu}_{2} \mathrm{VO}_{6}$ [23] and $\mathrm{BiZn}_{2} \mathrm{VO}_{6}$ [24]. That is due to, to date all the grown $\mathrm{BiM}_{2} \mathrm{AO}_{6}$ compounds were to our knowledge prepared for growth durations more than $10 \mathrm{~h}$ and by high-temperature $\left(\geq 700{ }^{\circ} \mathrm{C}\right)$ solid-state reactions $[23$ 25]. This render them expensive and does not allow neither a doping using an organic compound as a means to control the nanostructure morphology nor the utilization of soft substrates. Instead, aqueous chemical growth (ACG), "green chemistry", is a low-temperature method for production of metal oxide nanostructures $[26,27]$. In addition to the low cost of this synthesis route, the ACG can be operated at sufficiently low-temperatures $\left(<100{ }^{\circ} \mathrm{C}\right)$.

In core-shell morphology, the inner nanostructure is encapsulated by outer shell of a different material. In addition, the hetero coupling of noble metallic nanomaterials ( $\mathrm{Ag}, \mathrm{Au}, \mathrm{Pd}$, etc.) to $\mathrm{ZnO}$ nanostructures is a widely accepted method to 
enhance the photocatalytic properties [28-30]. Besides these methods, semiconductor oxides and hydroxides have also been employed to the fabrication of heterostructures with $\mathrm{ZnO}$ nanostructures [31-33]. Moreover, layered double hydroxides (LDHs) have shown promising properties for photocatalysis and are considered the best replacement to $\mathrm{TiO}_{2}$ based photo-catalysts due to their layered structure, flexibility in composition, controlled dimension, low cost, and simple methodologies for preparation [34]. Among LDHs, the features of Ni-Fe are highly appealing such, facile fabrication availability, inexpensive, exhibit high specific surface area, high density of the active centers that can facilitate the interaction with different catalytic materials. Therefore, Ni-Fe (LDHs) might play an active role during coupling with $\mathrm{ZnO}$ and creates a synergistic effect, which could remain responsible for superior performance for photochemical water splitting in alkaline media. By harvesting these unique avenues of $\mathrm{Ni}$-Fe layered double hydroxides, and further the deposition of $\mathrm{Ni}-\mathrm{Fe}$ layered double hydroxide may prevent the dissolution of $\mathrm{ZnO}$ in aqueous solution under light irradiation and results in an efficient photocatalysis. Based on our knowledge, and reported literature there is no report about $\mathrm{Ni}-\mathrm{Fe}$ layered double hydroxide deposited on $\mathrm{ZnO}$ nanowires/nanorods for photochemical water splitting.

In this paper we present our recent results on the utilization of the photocatalytic properties of single, composite (mixed metal oxide), and core-shell nanostructures. We adopt the low temperature chemical approach for synthesizing all samples. Structural characterization and the utilization of all the synthesized samples for efficient optical processes is demonstrated.

\section{EXPERIMENTAL}

Below we discuss briefly the different metal oxide samples preparation. For all the samples, we followed low temperature chemical approach. Further, for all samples we have used analytical grade chemicals purchased form Sigma Aldrich and used without further purification.

\subsection{Magnesium doped ZnO NPs}

The ZnO NPs have been grown using the co-precipitation method according to our recent work [35]. However, as a brief explanation, two solutions of zinc acetate dehydrate $(0.1 \mathrm{M})$ and sodium hydroxide $(0.2 \mathrm{M})$ were prepared by dissolving them in deionized water and magnetically stirred overnight at room temperature. Then the two solution were mixed into one beaker and magnetically stirred at $750 \mathrm{rpm}$ for 2 hours under temperature of $60^{\circ} \mathrm{C}$ in a hot plate at room conditions. After 2 hours of stirring, the precipitated white milky solution was separated by centrifugation ( $4500 \mathrm{rpm}$ for 2 minutes). Afterward, the precipitation product was washed with distilled water and acetone. Finally, ZnO NPs in the form of powder was obtained by drying the precipitation product into a laboratory oven at $75^{\circ} \mathrm{C}$ for 6 hours. For Mg-doped $\mathrm{ZnO}$ NPs samples preparation, a diluted solution of magnesium nitrate hexahydrate with atomic concentration $7 \%$ was mixed with sodium hydroxide and stirred overnight at room temperature. Then mixed with zinc acetate dehydrate $(0.1 \mathrm{M})$ solution that stirred also overnight into one beaker and stirred at $750 \mathrm{rpm}$ for 2 hours under temperature of $60{ }^{\circ} \mathrm{C}$ in a hot plate at room conditions. After 2 hours of stirring, the precipitated was separated by centrifugation and then washed with distilled water and acetone. 


\section{$2.2 \mathrm{ZnO} / \mathrm{Ag} / \mathrm{Ag}_{2} \mathrm{WO}_{4}$ heterostructures}

The ZnO NRs were grown on an Au-coated glass that containing a seed layer of $\mathrm{ZnO} \mathrm{NPs}$, by low temperature aqueous chemical growth method [38]. The precursor solution was prepared by dissolving equal molecular $(0.05 \mathrm{M})$ of zinc nitrate hexahydrate and hexamethylenetetramine in deionized (DI) water. The prepared substrates that contain seed layer of $\mathrm{ZnO}$ NPs were immersed horizontally after they were fixed in Teflon sample holder into the precursor solution and loaded into a preheated oven at $90{ }^{\circ} \mathrm{C}$ for 5 hours. Then samples were cleaned with DI water to remove any undesired particles, and then dried with blowing nitrogen for few seconds.

$\mathrm{Ag} / \mathrm{Ag}_{2} \mathrm{WO}_{4}$ particles were deposit on the prepared $\mathrm{ZnO}$ NRs using SILAR method. An anionic and cationic aqueous precursor solution was prepared separately using $0.05 \mathrm{M}$ of silver nitrate and $0.05 \mathrm{M}$ of sodium tungstate, respectively. The deposition done by immersion of the above prepared $\mathrm{ZnO}$ NRs samples into silver nitrate solution for 2 minutes to absorb the silver ions $\left(\mathrm{Ag}^{+}\right)$and then they were washed with DI water to remove excess ions or any other particles. Then the sample immersed into the sodium tungstate solution for 2 minutes and again washed with DI water. This cycle was repeated for 15 times to obtain enough $\mathrm{Ag} / \mathrm{Ag}_{2} \mathrm{WO}_{4}$ nanoparticles on the $\mathrm{ZnO}$ NRs.

\subsection{Synthesis of $\mathrm{BiZn}_{2} \mathrm{VO}_{6}$}

A two-step low-temperature aqueous chemical growth (ACG) process was used to prepare the $\mathrm{BiZn}_{2} \mathrm{VO}_{6}$ compound nanostructures. Doped and undoped $\mathrm{ZnO}$ nanorods were prepared as previously reported [36]. Briefly, the growth solution used in this experiment was prepared from an equimolar concentration of $0.05 \mathrm{M}$ solutions of zinc nitrate hexahydrate $\mathrm{ZnNO}_{3} \cdot 6 \mathrm{H} 2 \mathrm{O}$ and hexamethylenetetramine $\left(\mathrm{C}_{6} \mathrm{H}_{12} \mathrm{~N}_{4}\right)$ in deionized water. For doped samples, the growth was also in the presence of $0.1 \%$ weight to volume (w/v) polyethylene glycol (PEG, molecular weight 2000). the homogenous solution was placed in an oven for 5 hours at $90{ }^{\circ} \mathrm{C}$. Afterwards, the separated precipitates were washed in deionized water and acetone, and then dried overnight at $60 \mathrm{oC}$. In the next step, the BiZn2VO6 compound was formed by adding a $0.10 \mathrm{~g}$ as-prepared PEG modified $\mathrm{ZnO} \mathrm{NRs}$ to $\mathrm{BiVO}_{4}$ growth solution. They were covered with aluminum foil and placed in the pre-heated oven for 4 at $80{ }^{\circ} \mathrm{C}$. BiVO4 growth solution was prepared according to Zhou's and coworkers report albeit at modified growth time [37]. In a typical synthetic route, equimolar concentration of $0.02 \mathrm{M}$ of bismuth (III) nitrate pentahydrate $(\mathrm{Bi}(\mathrm{NO} 3) 3 \cdot 5 \mathrm{H} 2 \mathrm{O})$ and ammonium metavanadate $\left(\mathrm{NH}_{4} \mathrm{VO}_{3}\right)$ were dissolved in $10 \mathrm{~mL}$ of nitric acid, 70\% (HNO3) solution. $20 \mathrm{~mL}$ deionized water was added into this solution under vigorous stirring until the salts were completely dissolved. Then, $\sim 12.8 \mathrm{~g}$ of sodium hydrogen carbonate (NaHCO3) was added to adjust the $\mathrm{pH}$ value to 6.5 until the formation of a yellow homogeneous solution. The final products were washed with deionized water and acetone, dried with nitrogen gas and then dried at $80^{\circ} \mathrm{C}$ for $10 \mathrm{~h}$ in the oven. Field emission scanning electron microscopy (SEM) for morphological analysis was performed by using a LEO 1550 Gemini field emission gun at $5 \mathrm{kV}$.

\subsection{Synthesis of the Ni-Fe layered double hydroxides (LDHs) /ZnO) nano-hetero-structures}

The Ni-Fe (LDHs)/ZnO nanostructures were prepared through three steps: the fabrication of ZnO NRs, the synthesis of $\mathrm{Ni}(\mathrm{OH})_{2} / \mathrm{ZnO}$ heterostructure precursors and $\mathrm{Ni}-\mathrm{Fe}(\mathrm{LDHs}) / \mathrm{ZnO}$ nanostructures 
The FTO substrates (surface resistivity $\sim 8 \Omega \mathrm{cm}^{-2}$ and transmittance $80-81.5 \%$ (visible)) used were first ultrasonically cleaned by acetone, isopropanol, and deionized (DI) water respectively each for $5 \mathrm{~min}$ and were then dried up using blowing nitrogen. Then, the FTO substrates were seeded with zinc acetate dehydrate layer via spin coating technique at $2000 \mathrm{rpm}$ for 30s. The seed solution of $0.01 \mathrm{M}$ zinc acetate dehydrate in $99 \%$ methanol was prepared at constant stirring and heating at $60{ }^{\circ} \mathrm{C}$. A solution of potassium hydroxide $(\mathrm{KOH})$ in methanol $(0.03 \mathrm{M})$ was added dropwise to this solution for a duration of 2 hours. This coating step was repeated three times to ensure uniform coverage of the $\mathrm{ZnO}$ seeds. This step was then followed by annealing in a normal laboratory oven for 10 minutes at $120^{\circ} \mathrm{C}$. Afterwards, the seed coated substrate were fixed horizontally upside-down in Teflon sample holder and kept in equimolar $0.05 \mathrm{M}$ solution of hexamethylenetetramine and zinc nitrate hexahydrate. The beaker containing the samples and the growth solution were covered with aluminium foil and placed in preheated laboratory oven at $90{ }^{\circ} \mathrm{C}$ for $5 \mathrm{~h}$. Finally, these samples were rinsed and cleaned deionized (DI) water and dried using blowing nitrogen.

For the photochemical deposition process, first an electrolyte was prepared by dissolving $0.15 \mathrm{M}$ of Ni $\left(\mathrm{NO}_{3}\right)_{2} 6 \mathrm{H}_{2} \mathrm{O}$ in $50 \mathrm{~mL}$ DI water under continuous stirring. Secondly the $\mathrm{ZnO}$ NRs were immersed into this electrolyte and potentiostatic deposition was carried out at a potential of $-1.0 \mathrm{~V}(\mathrm{vs} \mathrm{Ag} / \mathrm{AgCl}$ reference electrode) for $60 \mathrm{~s}$.

The $\mathrm{Ni}(\mathrm{OH})_{2} / \mathrm{ZnO}$ were immersed into an aqueous solution of $0.15 \mathrm{M}$ of $\mathrm{FeSO}_{4} 6 \mathrm{H}_{2} \mathrm{O}$ in $50 \mathrm{~mL}$ DI water under stirring in a $\mathrm{N}_{2}$ atmosphere to prevent the oxidation of $\mathrm{Fe}^{2+}$ and the potentiostatic deposition was carried out at a potential of -1.0 $\mathrm{V}(\mathrm{vs} \mathrm{Ag} / \mathrm{AgCl})$ for different durations.

\section{RESULTS AND DISCUSSION}

Figure 1 shows the XRD pattern of the synthesized pure and Mg-doped ZnO NPs samples. As can be seen the all obtained XRD diffraction peaks belong to the hexagonal wurtzite pure phase of $\mathrm{ZnO}$ with lattice parameters (JCPDS no. 36-1451) which suggest that there are no other phases of $\mathrm{ZnO}$ or impurities have been observed. Also, a similar XRD diffraction peaks were obtained from the Mg-doped $\mathrm{ZnO}$ NPs sample which confirm that there was no second phase such as $\mathrm{MgO}$ formed in the papered samples. In addition, lower intensities from Mg-doped ZnO NPs XRD diffraction peaks were observed. 


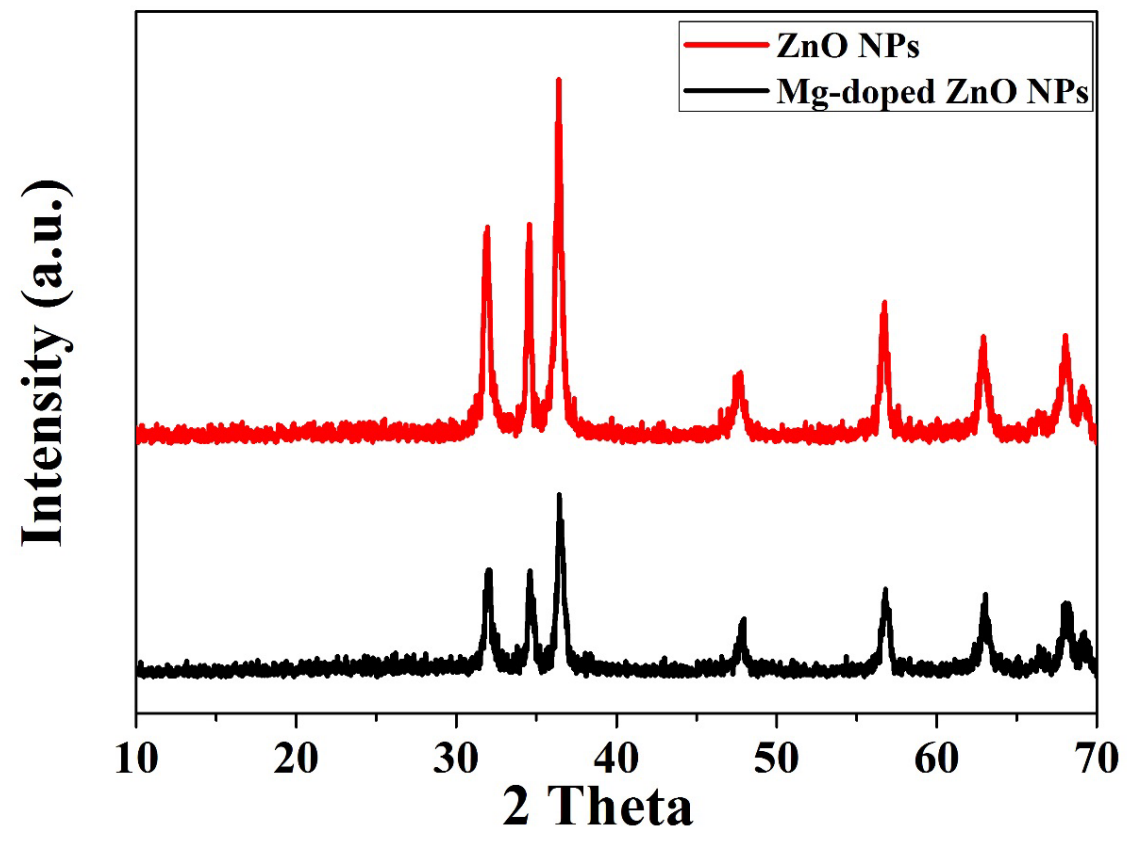

Figure 1. XRD spectra of the bare and magnesium doped ZnO NPs.

Figure 2 shows the FM-SEM images of the synthesized pure and Mg-doped ZnO NPs. As it can be seen, the pure ZnO NPs sample showed a better uniform size distribution as compared with Mg-doped ZnO NPs samples. From the FMSEM images, the NPs average size were estimated to be $\sim 58$, and $\sim 100 \mathrm{~nm}$ for pure ZnO NPs and Mg-doped ZnO NPs with $7 \%$ atomic weight doping concentration, respectively. The variation in the NPs average size might be due to the agglomeration of the small particles.
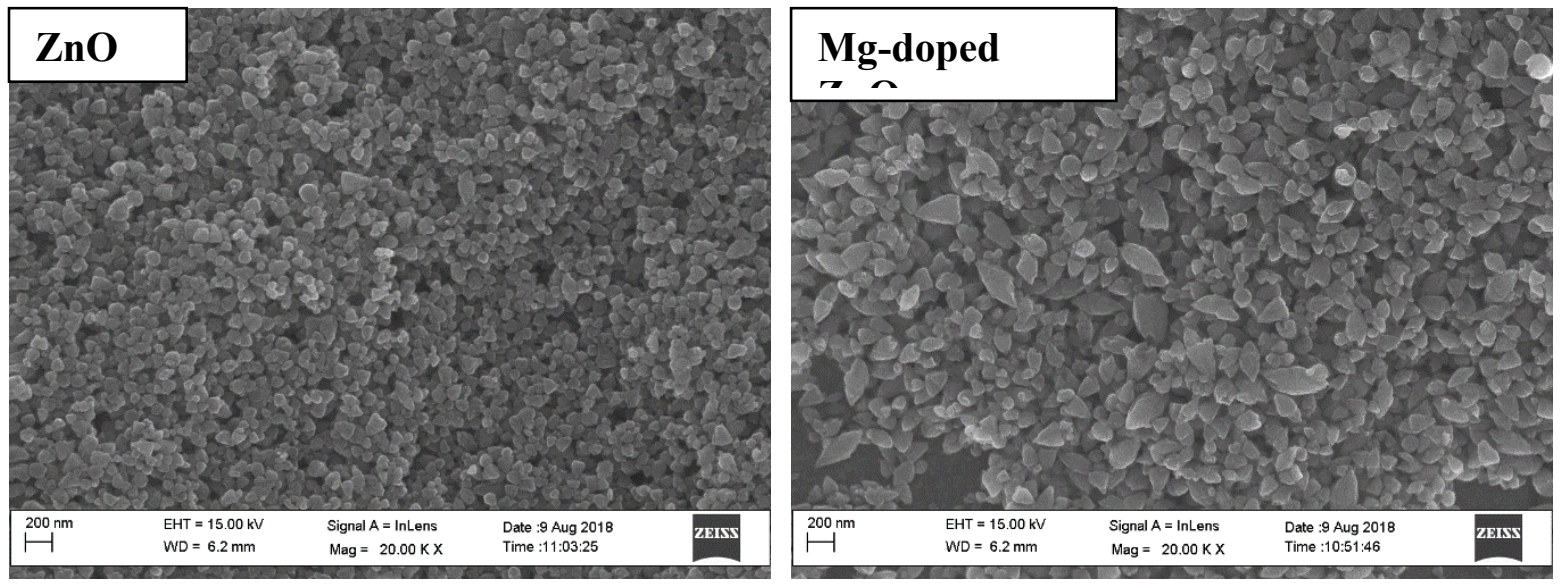

Figure 2. FM-SEM images of synthesized pure and Mg-doped $\mathrm{ZnO}$ NPs. 

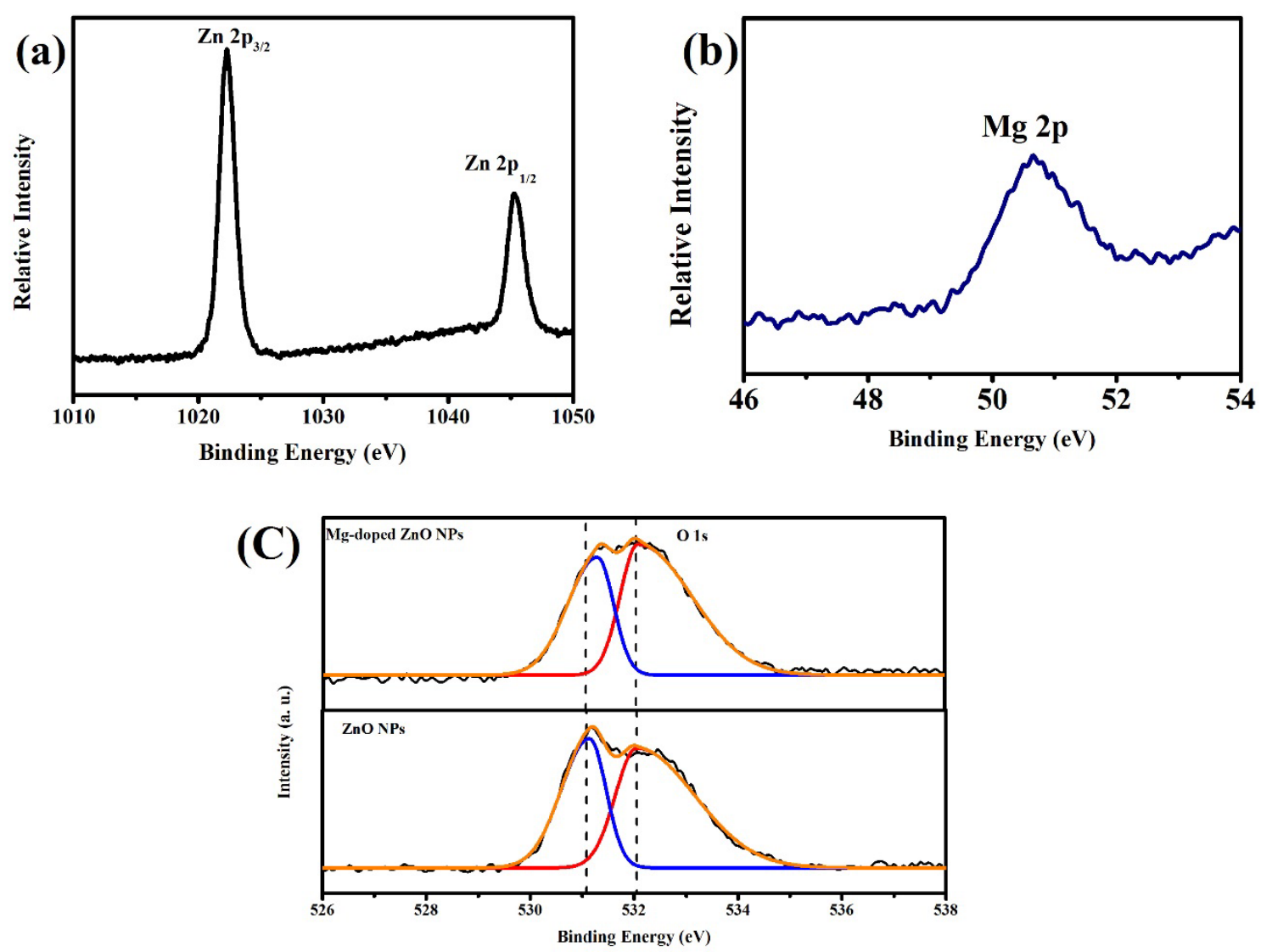

Figure 3. XPS core level spectra of (a) Zn 2p and, (b) Mg 2p, and (c) O1s of ZnO NPs and Mg-Doped ZnO NPs.

Figure 3 (a) shows the XPS core level spectra of Zn 2p of the synthesized pure ZnO NPs sample which is composed of two peaks centered 1022.3 and $1045.3 \mathrm{eV}$. These peaks are attributed to binding energy lines of $\mathrm{Zn} 2 \mathrm{p}_{3 / 2}$ and $\mathrm{Zn} 2 \mathrm{p}_{1 / 2}$
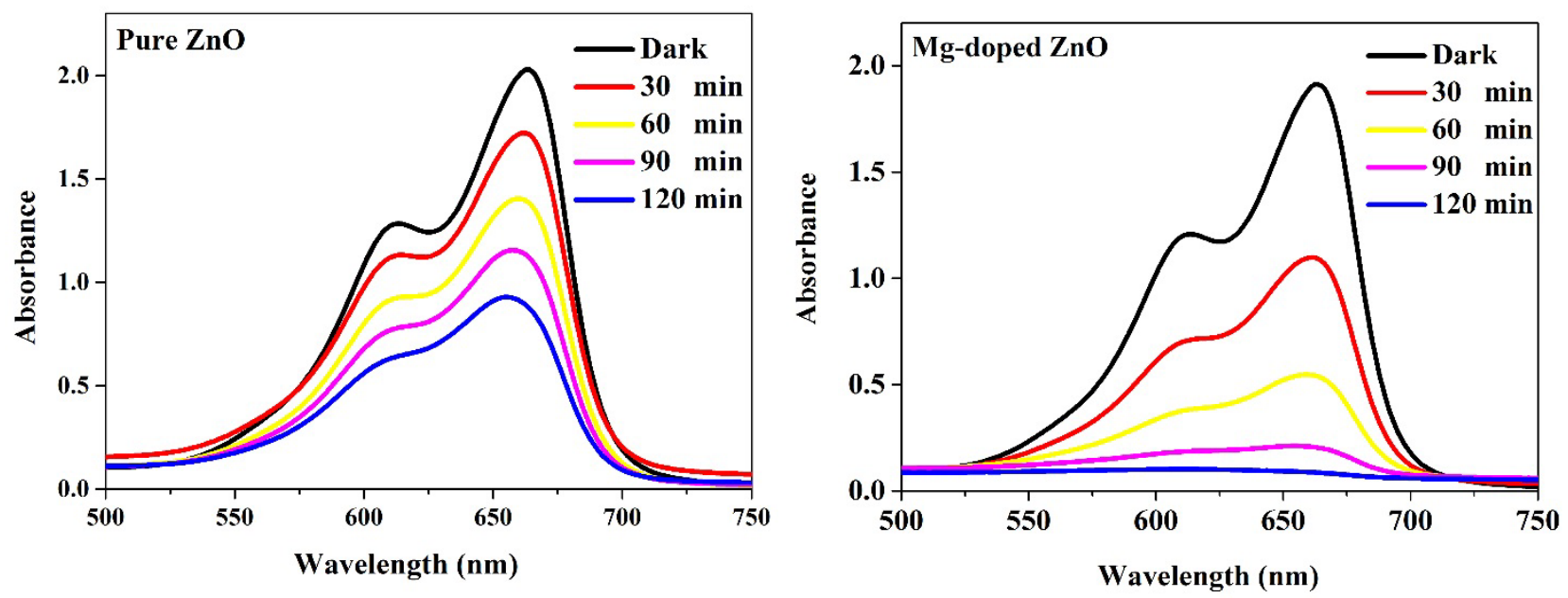

Figure 4. Absorbance spectra of MB during photocatalytic activities for pure and Mg-doped ZnO NPs under dark and solar light. 


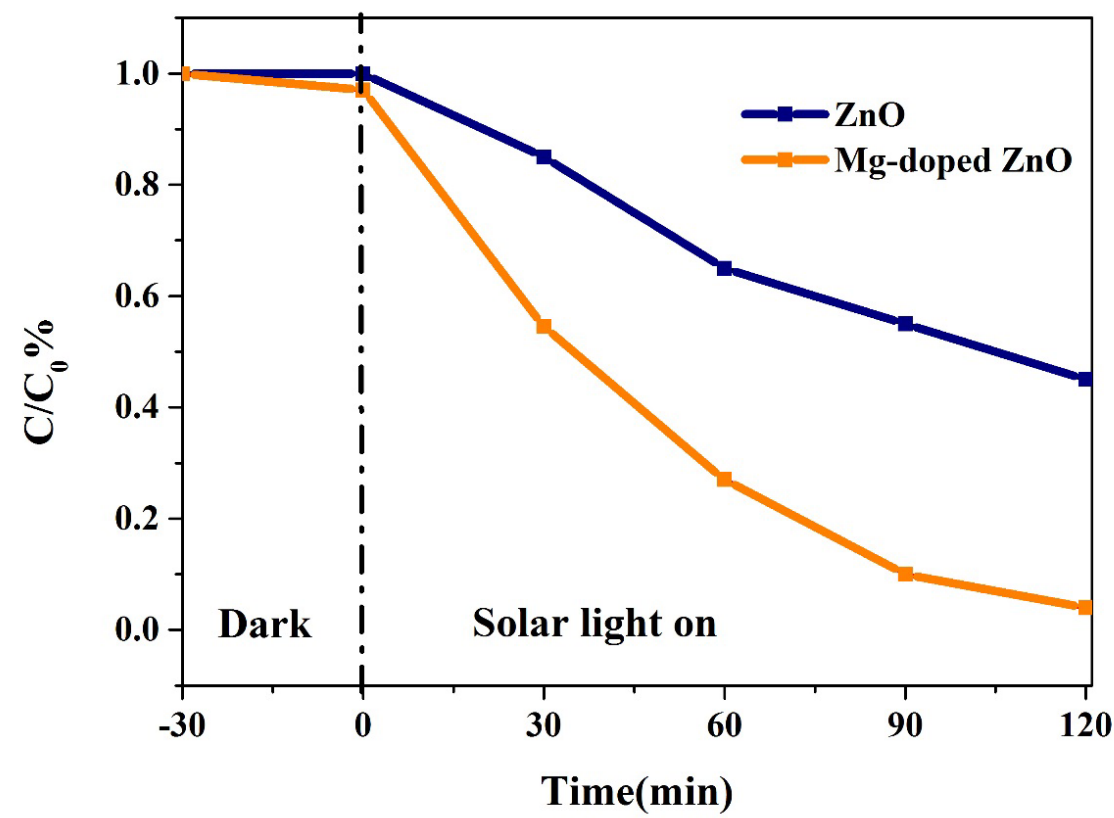

Figure 5. The concentration of MB during photocatalytic process for pure and Mg-doped ZnO NPs under dark and solar light.

and they explain the formation of $\mathrm{Zn}-\mathrm{O}$ bonds within the $\mathrm{ZnO}$ crystal lattice [39]. Fig.3 (b) shows the Mg 2p XPS peak of $\mathrm{Mg}$-doped $\mathrm{ZnO}$ with 7\% atomic weight of doping concentration. The peak is centered at $\sim 50 \mathrm{eV}$ which could be attributed to the presence of $\mathrm{Mg}^{2+}$ that replaces the $\mathrm{Zn}^{2+}$. The O1s core level XPS spectra of pure and Mg-doped $\mathrm{ZnO}$ NPs are shown in Fig. 3 (c), which decomposed into tow Gaussian peak. For pure ZnO NPs, the peak at low binding energy centered at $531.10 \mathrm{eV}$ could be related to $\mathrm{O}^{2-}$ ions $[39,41]$. Whereas the peak at higher binding energy centered at $532.05 \mathrm{eV}$ can be ascribed to the oxygen $\mathrm{O}_{2}$ on the $\mathrm{ZnO}$ surface and water molecules $\mathrm{H}_{2} \mathrm{O}$ [41].The $\mathrm{Mg}$-doped $\mathrm{ZnO}$ sample show slightly shift towards higher binding energy with two Gaussian peak centered at 531.26 and 532.07 and could be related to the formation of $\mathrm{Zn}-\mathrm{O}-\mathrm{Mg}$ bond and confirm that $\mathrm{Mg}^{2+}$ has substituted $\mathrm{Zn}^{2+}$. Figure 4 show the absorbance spectra of MB during the photodegradation reaction time of the synthesized pure and Mg-doped ZnO NPs samples. The absorption peak of the MB exhibits the main band at $663 \mathrm{~nm}$ and decreases with the irradiation time, which indicates the degradation of MB has taken place. The concentration of the dye $(\mathrm{C} / \mathrm{C} 0)$ versus illumination time of $\mathrm{MB}$ was calculated and presented in Fig. 5. 45\% of the dye was remain for the pure $\mathrm{ZnO}$, whereas only $4 \%$ was remain using $\mathrm{Mg}$-doped $\mathrm{ZnO}$. This result is probably due to the modifications of the physical and chemical properties of the $\mathrm{ZnO}$ by $\mathrm{Mg}$ doping $[42,43]$. When $\mathrm{Mg}^{2+}$ was introduced into the $\mathrm{ZnO}$ crystal lattice, more oxygen defects could be produced, which improve the separation and migration efficiency of the photo-generated of electrons-holes pairs. The result of that higher degradation efficiency was found from Mg-doped $\mathrm{ZnO}$ NPs. 

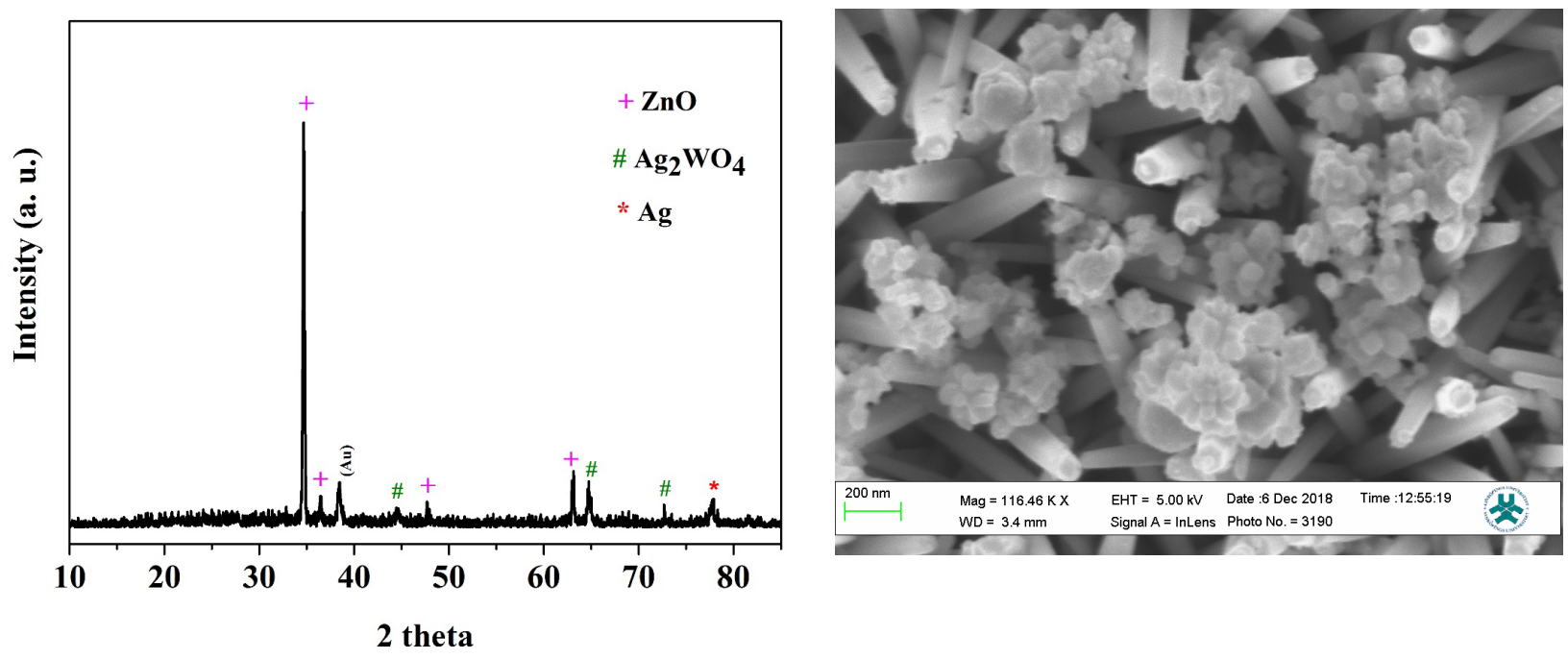

Figure 6 (Left). XRD patterns of the $\mathrm{ZnO} \mathrm{NRs}$ and the $\mathrm{ZnO} / \mathrm{Ag} / \mathrm{Ag}_{2} \mathrm{WO}_{4}$ heterostructure. Figure 7 (Right). FM-SEM image of the $\mathrm{ZnO} / \mathrm{Ag} / \mathrm{Ag}_{2} \mathrm{WO}_{4}$ heterostructure.

Figure 6 shows the structural characteristics obtained by XRD for the $\mathrm{ZnO} / \mathrm{Ag} / \mathrm{Ag}_{2} \mathrm{WO}_{4}$ heterostructures. It could be observed that the XRD diffraction peaks of the planes (002), (101), (102), and (103) are belonging to the hexagonal wurtzite pure phase of ZnO (JCPDS no. 36-1451) which suggest that there are no other phases of ZnO or impurities have been observed. The planes of (042), (025), and (135) were assigned for $\mathrm{Ag}_{2} \mathrm{WO}_{4}$ (JCPDS no 33-1195). The peak at $2 \theta$ equal to $78^{\circ}$ is assigned to the reflections of cubic Ag (JCPDS no 65-2871). Figure 7 shows the morphology of $\mathrm{ZnO} / \mathrm{Ag} / \mathrm{Ag}_{2} \mathrm{WO}_{4}$ heterostructure that was measured by the FE-SEM imaging. It could be observed that the $\mathrm{ZnO} \mathrm{NRs}$ were vertically aligned and with hexagonal shape and estimated diameter size of $\sim 100 \mathrm{~nm}$. Also, the $\mathrm{Ag} / \mathrm{Ag}_{2} \mathrm{WO}_{4}$ could observed clearly distributed on the surface of $\mathrm{ZnO}$ NRs indicating the formation of $\mathrm{ZnO} / \mathrm{Ag} / \mathrm{Ag}_{2} \mathrm{WO}_{4}$ heterostructure.

Figure 8 shows The plot of $(\alpha \mathrm{h} v) 2$ versus the $(\mathrm{h} v)$ to estimate the band gap of the $\mathrm{ZnO}$ NRs and the $\mathrm{ZnO} / \mathrm{Ag} / \mathrm{Ag} 2 \mathrm{WO} 4$ heterostructure. The optical band gaps were found to be 3.2 and $3.1 \mathrm{eV}$ for $\mathrm{ZnO}$ and $\mathrm{ZnO} / \mathrm{Ag} / \mathrm{Ag}_{2} \mathrm{WO}_{4}$ heterostructures, respectively. This result could be explained due to formation of $\mathrm{Ag}_{2} \mathrm{WO}_{4}$ on the top of the $\mathrm{ZnO} \mathrm{NRs}$ forming the heterostructure (i. e. bandgap engineering) which led to increase the band gap of the $\mathrm{ZnO}$ slightly. It is worth to note that metallic silver could be produced during the sample preparation and can trigger surface plasmonic effect $[14,16]$. 

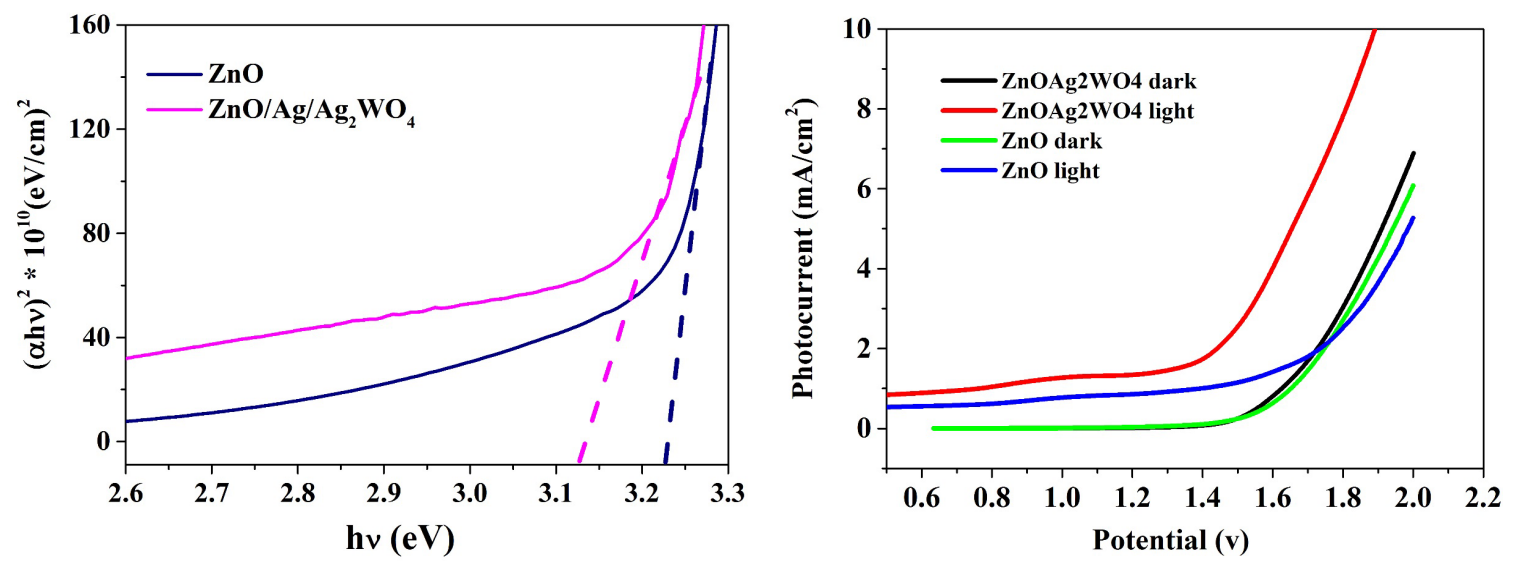

Figure 8 (Left). The plot of $(\alpha \mathrm{h} v) 2$ versus the $(\mathrm{h} v)$ to estimate the band gap of the $\mathrm{ZnO} \mathrm{NRs}$ and the $\mathrm{ZnO} / \mathrm{Ag} / \mathrm{Ag} 2 \mathrm{WO} 4$ heterostructure. Figure 9 (Right). Linear sweep voltammetry curves of the $\mathrm{ZnO} \mathrm{NRs}$, and the $\mathrm{ZnO} / \mathrm{Ag} / \mathrm{Ag} 2 \mathrm{WO} 4$ photo-electrodes under light and dark conditions.

The photoelectrochemical activities were studied by using three electrode photoelectrochemical measurements using SP200 potentiostat (Bio-Logic, Claix, France). A platinum (Pt) sheet was used as the counter electrode and a standard $\mathrm{Ag} / \mathrm{AgCl}$ in $3 \mathrm{M} \mathrm{KCl}$ (as a reference electrode) was used with $(0.1 \mathrm{M})$ of sodium sulfate $\left(\mathrm{Na}_{2} \mathrm{SO}_{4}\right)$ electrolyte. The total area of the electrode that immersed in the electrolyte was $1 \mathrm{~cm}^{2}$. The sun light was obtained by a solar simulator that uses a $100 \mathrm{~W}$ ozone free xenon lamp with an output power of 1 sun (AM 1.5). Figure 9 shows the linear sweep voltammetry measurements for both pristine $\mathrm{ZnO}$ NRs and $\mathrm{ZnO} / \mathrm{Ag} / \mathrm{Ag}_{2} \mathrm{WO}_{4}$ photoelectrodes. A reasonable response upon illumination by solar light was observed, whereas the response at dark is relatively very low with flat curves. However, the I-V curve of the $\mathrm{ZnO} / \mathrm{Ag} / \mathrm{Ag}_{2} \mathrm{WO}_{4}$ photo-electrode under simulated sun light confirms a higher photoelectric conversion than that of the $\mathrm{ZnO}$ NRs photo-electrode. The observed photocurrent density at the potential of $1.23 \mathrm{~V}$ (vs. $\mathrm{Ag} / \mathrm{AgCl}$ ) is $0.9 \mathrm{~mA} / \mathrm{cm}^{2}$ for $\mathrm{ZnO} \mathrm{NRs}$ and increased to $1.4 \mathrm{~mA} / \mathrm{cm}^{2}$ for the $\mathrm{ZnO} / \mathrm{Ag} / \mathrm{Ag}_{2} \mathrm{WO}_{4}$ photo-electrode. This result might be attributed to the higher separation and transportation of photo-induced charge carriers [44] due to the presence of the $\mathrm{Ag} / \mathrm{Ag}_{2} \mathrm{WO}_{4}$ particles that might change the band gap of the heterostructure. moreover, the presence of metallic $\mathrm{Ag}^{0}$ particles would enhance the absorption of visible light and then improve the separation rate of the photogenerated electrons-holes pairs because of the SPR [14].

The photocatalytic performance of the prepared $\mathrm{BiZn}_{2} \mathrm{VO}_{6}$ compound nanostructures was measured by through the photodegradation of $20 \mathrm{mg} \mathrm{L}^{-1}$ Congo red (CR), solutions as the pollutant. The light source was a $300 \mathrm{~W}$ xenon lamp used without any filter to simulate sunlight irradiation. At first, $50 \mathrm{mg}$ photocatalyst was dispersed in a $100 \mathrm{~mL}$ dye aqueous solution, and the suspension was stirred in the dark for 30 minutes to ensure the adsorption-desorption equilibrium between the photocatalyst and the dye molecules prior to the exposure to the simulated solar irradiation. While the lamp was turned on, the samples were taken in specific desired time intervals within 90 minutes of the reaction time. The change in the concentration of the dye solution was measured using UV-vis absorption spectroscopy at the characteristic absorption wavelength of 497,664 , and $553 \mathrm{~nm}$ for $\mathrm{CR}$. 

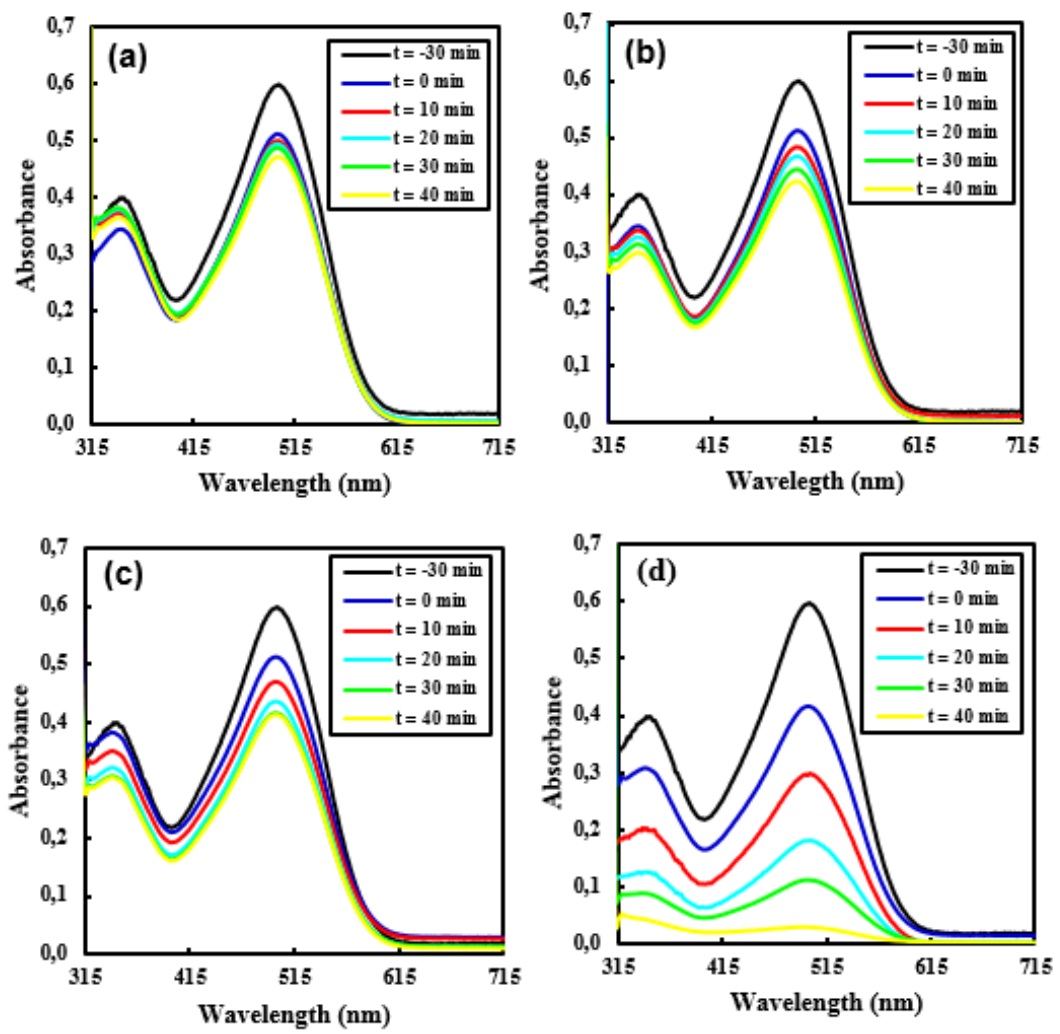

Figure 10. UV-vis spectra for degradation of Congo red under solar irradiation over the (a) PEG doped $\mathrm{ZnO}^{\mathrm{NRs}}$, (b) $\mathrm{BiVO}$, (b) $\mathrm{BiZn}_{2} \mathrm{VO}_{6}$, and (d) PEG doped $\mathrm{BiZn}_{2} \mathrm{VO}_{6}$.

SEM imaging (not shown here) was carried out to determine the morphology of the different $\mathrm{ZnO} / \mathrm{BiZn}_{2} \mathrm{VO}_{6}$ nanocompounds. In order to identify possible changes of the $\mathrm{ZnO}$ nanorods during $\mathrm{BiZn}_{2} \mathrm{VO}_{6}$ growth, we examined $\mathrm{ZnO}$ nanorods films that were exposed to a modified $\mathrm{BiZn}_{2} \mathrm{VO}_{6}$ growth solution not containing the actual growth material. Comparing the initial $\mathrm{ZnO}$ nanorods and the post-treated films shows that there is a clear etching effect of the nanorods, and they are reformed into nanobelts. The lengths of these $\mathrm{ZnO}$ NBs were about 3-5 $\mu \mathrm{m}$, their average side thickness is around $100 \mathrm{~nm}$, and their widths range between around 300 and $700 \mathrm{~nm}$. The morphology of $\mathrm{ZnO}$ nanostructures is known to be sensitive to external conditions like $\mathrm{pH}$, and we attributed the observed morphological change to the lower $\mathrm{pH}$ of the $\mathrm{BiZn}_{2} \mathrm{VO}_{6}$ growth solution $(\mathrm{pH} \approx 6.0-6.5)$ compared with the growth solution of the initial $\mathrm{ZnO}$ nanorods ( $\mathrm{pH}$ $\approx 6.5$ and 7). The samples were investigated after growth of the PEG-doped $\mathrm{BiZn}_{2} \mathrm{VO}_{6}$ nano-compound by ACG. The nanocompounds have a rice-like shape, with average height of 1.3-1.8 $\mu \mathrm{m}$ and widths between $1.9 \mu \mathrm{m}$ and $2.6 \mu \mathrm{m}$. As clearly seen on the SEM pictures the agglomeration and the size of $\mathrm{BiZn}_{2} \mathrm{VO}_{6}$ capped $\mathrm{ZnO} \mathrm{NBs}$. 

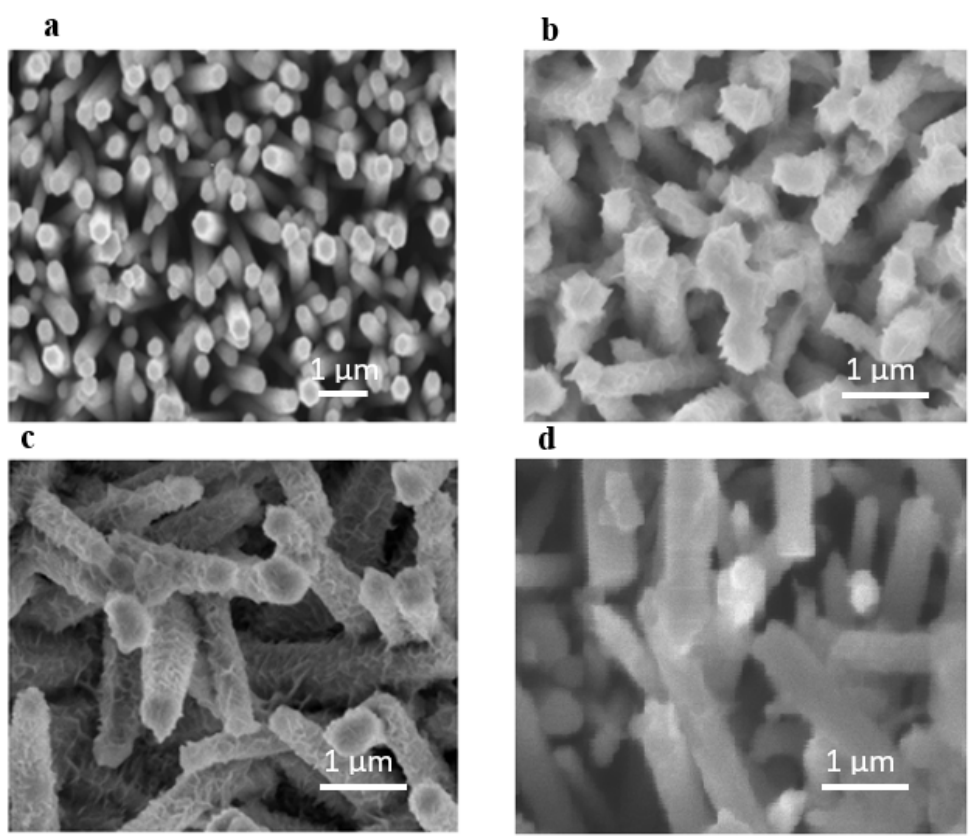

Figure 11. (a) Pure ZnO NRs grown on FTO glass substrated, (b) Ni-Fe LDHs/ZnO at 10 seconds deposition, (c) Ni-Fe(LDHs)/ZnO 20 seconds deposition, and (d) $\mathrm{Ni}-\mathrm{Fe}(\mathrm{LDHs}) / \mathrm{ZnO} 30$ seconds deposition.

The CR was chosen as the typical refractory dye to assess the photocatalytic performance of the obtained samples. Figure 11 shows UV-vis spectra of the visible-light induced PEG-doped $\mathrm{BiZn}_{2} \mathrm{VO}_{6} \mathrm{NCs}$ photocatalytic degradation of Congo red dye. Changes in the UV-vis absorbance spectra of $\mathrm{CR}$ as a function of irradiation time in the presence of PEG modified $\mathrm{ZnO} N R s, \mathrm{BiVO}_{4}, \mathrm{BiZn}_{2} \mathrm{VO}_{6}$, and $\mathrm{PEG}$ doped $\mathrm{BiZn}_{2} \mathrm{VO}_{6}(0.10 \% \mathrm{w} / \mathrm{v})$ samples are shown in Fig. 11 (a-d). Obviously, the characteristic absorption peak of Congo red just diminishes a little over the PEG modified ZnO NRs, $\mathrm{BiVO}_{4}, \mathrm{BiZn}_{2} \mathrm{VO}_{6}$ samples with the prolongation of light time. However, as shown in Fig. $(11 \mathrm{~d})$, the intensity of the major peak has rapidly weakened until being very smooth, indicating that the CR structure was successfully restructured by the PEG doped $\mathrm{BiZn}_{2} \mathrm{VO}_{6}(0.10 \% \mathrm{w} / \mathrm{v})$ photocatalyst. Although $\mathrm{BiVO}_{4}$ can strongly adsorb visible light due to the narrow band-gap energy. However, The $0.1 \%$ (w/v) PEG-doped $\mathrm{ZnO}$ NRs doped $\mathrm{BiVO}_{4}$ nanocompounds was found to be the optimal for Cong red degradation under simulated solar light. We noted that, after 40 minutes the Cong red is $97 \%$ degraded. Clearly, the introduction of PEG enhanced the photocatalytic degradation ability of $\mathrm{BiZn}_{2} \mathrm{VO}_{6}$. This can be explained as follows: The synergistic effect of $\mathrm{PEG}$ and $\mathrm{BiZn}_{2} \mathrm{VO}_{6}$ has greatly promoted the separation of the photoinduced electrons and holes, which has a positive effect on the photocatalytic reactions. 

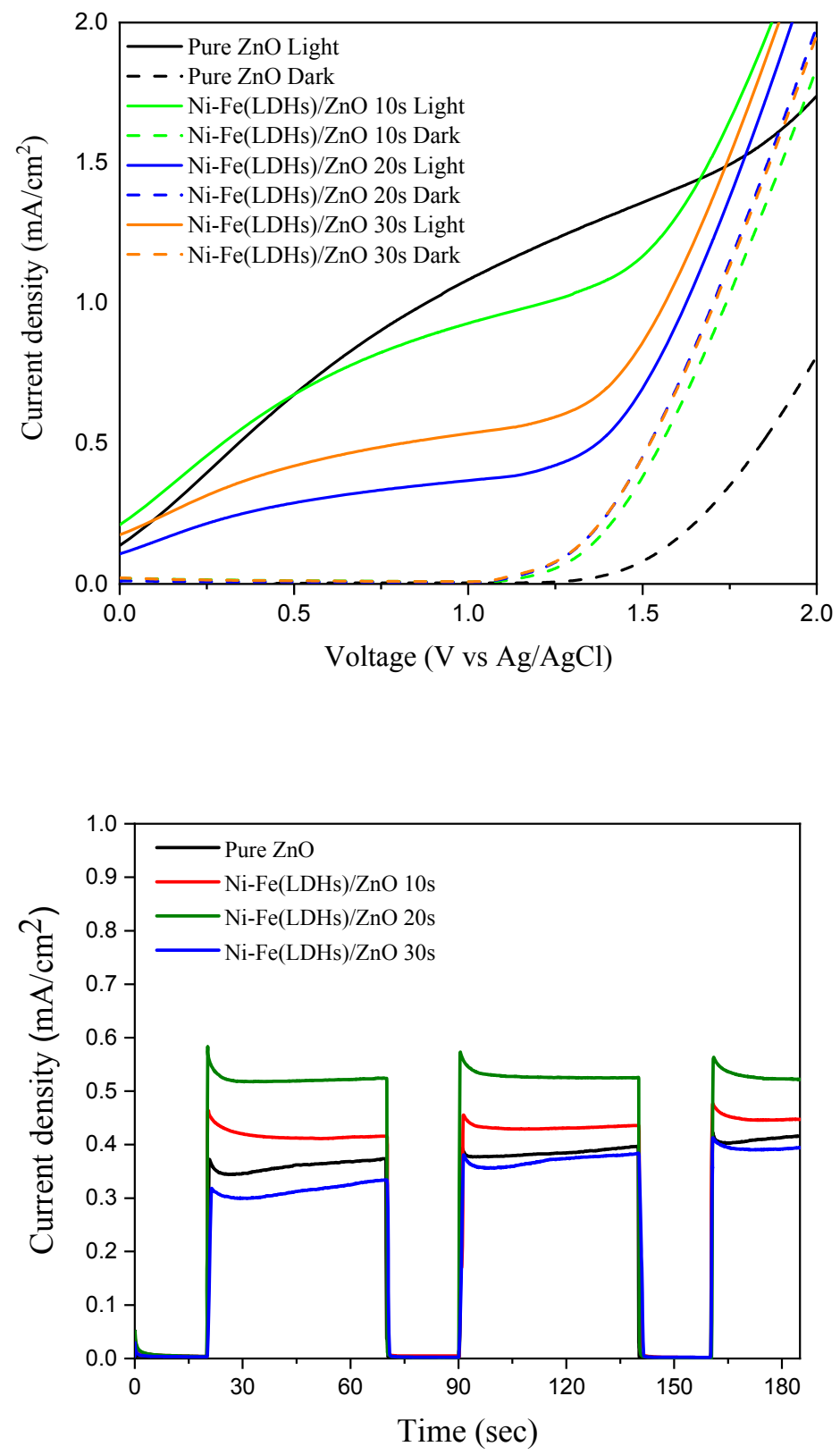

Figure 12. (Above). The I-V curve of pure $\mathrm{ZnO} \mathrm{NRs}, \mathrm{Ni}-\mathrm{Fe}(\mathrm{LDHs}) / \mathrm{ZnO} 10$ seconds, Ni-Fe(LDHs)/ZnO 20 seconds, and Ni$\mathrm{Fe}(\mathrm{LDHs}) / \mathrm{ZnO} 30$ seconds under the illumination of light and dark. (Below) ) Photo response of pure $\mathrm{ZnO} \mathrm{NRs}, \mathrm{Ni}-\mathrm{Fe}(\mathrm{LDHs}) / \mathrm{ZnO}$ 10 seconds, $\mathrm{Ni}-\mathrm{Fe}(\mathrm{LDHs}) / \mathrm{ZnO} 20$ seconds, and $\mathrm{Ni}-\mathrm{Fe}(\mathrm{LDHs}) / \mathrm{ZnO} 30$ seconds.

The morphological features of the $\mathrm{Ni}-\mathrm{Fe}(\mathrm{LDHs}) / \mathrm{ZnO}$ were investigated by scanning electron microscopy as depicted in Figure 10. Figure 10 a show a hexagonal facets structure of $\mathrm{ZnO}$ NRs as expected. However, the deposition of the Ni-Fe 
layered double hydroxide on the $\mathrm{ZnO}$ NRs indicates a core-shell morphology as depicted in Figure $10 \mathrm{c}$. The layer thickness is not increased significantly for longer deposition durations.

The photoelectrochemical response of various, $\mathrm{Ni}-\mathrm{Fe}(\mathrm{LDHs}) / \mathrm{ZnO}$ photo-anodes was measured in $1 \mathrm{M} \mathrm{KOH}$ solution of $\mathrm{pH}$ 14. Figure 12 (Above) shows the LSV response for pure ZnO NRs, Ni-Fe (LDHs)/ZnO at 10 seconds deposition, $\mathrm{Ni}-\mathrm{Fe}(\mathrm{LDHs}) / \mathrm{ZnO}$ at 20 seconds deposition, and $\mathrm{Ni}-\mathrm{Fe}(\mathrm{LDHs}) / \mathrm{ZnO}$ at 30 seconds deposition. Importantly, in dark the response of photo-anodes is very weak and requires more potential for water oxidation. However, with illumination of 1 Sun (AM 1.5G) of light there is a drastic decrease in the redox potential of water, still higher potential is required which is due to the fact part of energy is required fo the oxidation provided by the light. The Ni-Fe layered double hydroxide/ $\mathrm{ZnO}$ showed the maximum response and the lowest redox potential for water oxidation that could be assigned to the tuned properties of $\mathrm{ZnO}$ after the deposition of the Ni-Fe layered double hydroxide that created the chemical coupling and the synergistic effects during the chemical growth. Figure 12 (Below) shows the photocurrent response under the illumination and dark conditions, photo response is fast and stable and the photo-anode of Ni-Fe layered double hydroxide with deposition of $20 \mathrm{~s}$ is giving high photocurrent and stable response due to tedious photocatalytic activity of the hybrid material.

\section{CONCLUSION}

In summary we have shown the potential of the low chemical approach as a useful strategy to synthesize high quality metal oxide nanostructures from different materials as well as for obtaining different morphologies. Among the investigated nanostructures, bare $\mathrm{ZnO} \mathrm{NPs}$ as well as magnesium doped, were utilized for photodegradation of methylene blue using sun light. The results showed that doping can improve the degradation efficiency. Starting by synthesizing $\mathrm{ZnO} \mathrm{NRs}$, we further processed with more steps to obtain $\mathrm{ZnO} / \mathrm{Ag} / \mathrm{Ag}_{2} \mathrm{WO}_{4}$ heterostructures. Such heterostructure with ionic silver has indicated further efficiency due to the plasmonic effect which further enhance the photocatalytic and photochemical properties. $\mathrm{BiZn}_{2} \mathrm{VO}_{6}$ compound nanostructures were also synthesized and utilized for the degradation of Congo red dye. Here both bare as well as $\mathrm{BiZn}_{2} \mathrm{VO}_{6}$ compound nanostructures were utilized. Again, doping indicated that it can be utilized for tuning and improving the photocatalytic efficiency. Finally, the photoelectrochemical response of various, $\mathrm{Ni}-\mathrm{Fe}$ (LDHs)/ZnO photo-anodes was investigated and promising results were observed. In general the demonstrated results in this paper indicated that metal oxide nanostructures could be a popular alternative for many photocatalytic, photoelectrochemical processes. This is due to the rather high efficiency, easy for synthesis with possibility of scale-up for industrial production, and the possibility of utilizing sun radiation.

\section{REFERENCES}

[1] Barreca, D., Carraro, G., Gasparotto, A., Maccato, C., Altantzis, T., Sada, C., Kaunisto, K., Ruoko, T.-P. and Bals, S., "Vapor Phase Fabrication of Nanoheterostructures Based on ZnO for Photoelectrochemical Water Splitting," Advanced Materials Interfaces 4(18), 1700161. 
[2] Hernández, S., Hidalgo, D., Sacco, A., Chiodoni, A., Lamberti, A., Cauda, V., Tresso, E. and Saracco, G., "Comparison of photocatalytic and transport properties of $\mathrm{TiO}_{2}$ and $\mathrm{ZnO}$ nanostructures for solar-driven water splitting," Physical Chemistry Chemical Physics 17(12), 7786 (2015).

[3] Zamiri, R., Ahangar, H. A., Tobaldi, D. M., Rebelo, A., Seabra, M. P., Shabani, M. and Ferreira, J. M. F., "Fabricating and characterising $\mathrm{ZnO}-\mathrm{ZnS}-\mathrm{Ag} 2 \mathrm{~S}$ ternary nanostructures with efficient solar-light photocatalytic activity," Phys. Chem. Chem. Phys. 16(40), 22425 (2014).

[4] Zhang, H., Chen, G. and Bahnemann, D. W., "Photoelectrocatalytic materials for environmental applications," Journal of Materials Chemistry 19(29), 5089 (2009).

[5] Ishihara, H., K. Kannarpady, G., R. Khedir, K., Woo, J., Trigwell, S. and S. Biris, A., "A novel tungsten trioxide (WO3)/ITO porous nanocomposite for enhanced photo-catalytic water splitting," Physical Chemistry Chemical Physics 13(43), 19560 (2011).

[6] Zhou, R., Lin, S., Zong, H., Huang, T., Li, F., Pan, J. and Cui, J., "Continuous Synthesis of Ag/TiO 2 Nanoparticles with Enhanced Photocatalytic Activity by Pulsed Laser Ablation,” Journal of Nanomaterials 2017, 9 (2017).

[7] Liu, Q., Cao, F., Wu, F., Tian, W. and Li, L., "Interface reacted ZnFe 2 O 4 on $\alpha$-Fe2O3 nanoarrays for largely improved photoelectrochemical activity," RSC Advances 5(97), 79446 (2015).

[8] K. Bora, D. and Braun, A., "Solution processed transparent nanoparticulate $\mathrm{ZnO}$ thin film electrode for photoelectrochemical water oxidation," RSC Advances 4(45), 23570 (2014).

[9] Ng, Y. H., Iwase, A., Kudo, A. and Amal, R., "Reducing Graphene Oxide on a Visible-Light $\mathrm{BiVO}_{4} \mathrm{Photocatalyst}$ for an Enhanced Photoelectrochemical Water Splitting. phys. chem. lett. 1(17) 2612 (2010)

[10] J. L. Yang S. J. An W. I. Park G.-C. Yi W. Choi "Photocatalysis Using ZnO Thin Films and Nanoneedles Grown by Metal-Organic Chemical Vapor Deposition” Advanced Materials.(2004)

[11] Kumar, S. G. and Rao, K. S. R. K., "Zinc oxide based photocatalysis: tailoring surface-bulk structure and related interfacial charge carrier dynamics for better environmental applications,” RSC Advances 5(5), 3351 (2015).

[12] Xu, S. and Wang, Z. L., "One-dimensional ZnO nanostructures: Solution growth and functional properties," Nano Res. 4(11), 1098 (2011).

[13] Fragua, D. M., Abargues, R., Rodriguez-Canto, P. J., Sanchez-Royo, J. F., Agouram, S. and Martinez-Pastor, J. P., “Au-ZnO Nanocomposite Films for Plasmonic Photocatalysis,” Advanced Materials Interfaces 2(11), 1500156.

[14] Pirhashemi, M. and Habibi-Yangjeh, A., "Ultrasonic-assisted preparation of plasmonic $\mathrm{ZnO} / \mathrm{Ag} / \mathrm{Ag}_{2} \mathrm{WO}_{4}$ nanocomposites with high visible-light photocatalytic performance for degradation of organic pollutants," Journal of Colloid and Interface Science 491, 229 (2017).

[15] Cai, L., Ren, F., Wang, M., Cai, G., Chen, Y., Liu, Y., Shen, S. and Guo, L., "V ions implanted ZnO nanorod arrays for photoelectrochemical water splitting under visible light," International Journal of Hydrogen Energy 40(3), 1401 (2015).

[16] Pirhashemi, M. and Habibi-Yangjeh, A., "Preparation of novel nanocomposites by deposition of $\mathrm{Ag}_{2} \mathrm{WO}_{4}$ and $\mathrm{AgI}$ over $\mathrm{ZnO}$ particles: Efficient plasmonic visible-light-driven photocatalysts through a cascade mechanism," Ceramics International 43(16), 13460 (2017). 
[17] Hashim, N. H., Subramani, S., Devarajan, M. and Ibrahim, A. R., "Properties of undoped ZnO and Mg doped $\mathrm{ZnO}$ thin films by sol-gel method for optoelectronic applications," Journal of the Australian Ceramic Society 53(2), 431 (2017).

[18] Arshad, M., Meenhaz Ansari, M., Ahmed, A. S., Tripathi, P., Ashraf, S. S. Z., Naqvi, A. H. and Azam, A., "Band gap engineering and enhanced photoluminescence of $\mathrm{Mg}$ doped $\mathrm{ZnO}$ nanoparticles synthesized by wet chemical route," Journal of Luminescence 161, 280 (2015).

[19] Elangovan, S. V., Sivakumar, N. and Chandramohan, V., "Magnesium doped zinc oxide nanocrystals for photocatalytic applications," Journal of Materials Science: Materials in Electronics 26(11), 8759 (2015).

[20] Vignesh, K. and Kang, M., "Facile synthesis, characterization and recyclable photocatalytic activity of Ag2WO4@g-C3N4,” Materials Science and Engineering: B 199, 36 (2015).

[21] Li, J., Yu, C., Zheng, C., Etogo, A., Xie, Y., Zhong, Y. and Hu, Y., "Facile formation of $\mathrm{Ag}_{2} \mathrm{WO}_{4} / \mathrm{AgX}(\mathrm{X}=\mathrm{Cl}, \mathrm{Br}$, I) hybrid nanorods with enhanced visible-light-driven photoelectrochemical properties," Materials Research Bulletin 61, 320 (2015).

[22] Zhang, S., Liu, Z., Zhang, Y., Gao, S., Jin, R. and Wang, Q., "Highly effective photoelectrochemical performance of solar energy materials based on $\mathrm{Ag}_{2} \mathrm{WO}_{4}-\mathrm{AgX}(\mathrm{X}=\mathrm{Cl}, \mathrm{Br}$, I) sensitized $\mathrm{TiO} 2$ nanotube arrays," Ceramics International 44(6), 6665 (2018).

[23] H. Liu, R. Nakamura and Y. Nakato, Bismuth-copper vanadate $\mathrm{BiCu}_{2} \mathrm{VO}_{6}$ as a novel photocatalyst for efficient visible-light-driven oxygen evolution, ChemPhysChem, 6, 2499 (2005).

[24] H. Liu, R. Nakamura and Y. Nakato, A visible-light responsive photocatalyst, BiZn2VO6, for efficient oxygen photoevolution from aqueous particulate suspensions, Electrochem. Solid-State Lett., 9, G187 (2006).

[25] S. E. Nunes, C.-H. Wang, K. So, J. S. O. Evans and I. R. Evans, Bismuth zinc vanadate, $\mathrm{BiZn}_{2} \mathrm{VO}_{6}$ : New crystal structure type and electronic structure, J. Solid State Chem., 2015, 222, 12 (2015).

[26] L. Vayssieres, Growth of Arrayed Nanorods and Nanowires of ZnO from Aqueous Solutions. Adv. Mater.15, 464 (2003).

[27] S. Elhag, Z. H. Ibupoto, V. Khranovskyy, M. Willander and O. Nur, Habit-modifying additives and their morphological consequences on photoluminescence and glucose sensing properties of $\mathrm{ZnO}$ nanostructures, grown via aqueous chemical synthesis, Vacuum 116, 21 (2015).

[28] Y. Zheng, L. Zheng, Y. Zhan, X. Lin, Q. Zheng, K. Wei, Ag/ZnO Heterostructure Nanocrystals: Synthesis, Characterization, and Photocatalysis, Inorganic Chemistry 46, (2007), 6980-6986 (2007).

[29] L. Shen, N. Bao, K. Yanagisawa, Y. Zheng, K. Domen, A. Gupta, C. Grimes, Direct growth of comet-like superstructures of $\mathrm{Au}-\mathrm{ZnO}$ submicron rod arrays by solvothermal soft chemistry process, Journal of Solid State Chemistry 180, 213-220 (2007).

[30] C. Liewhiran, S. Phanichphant, Doctor-bladed thick films of flame-made Pd/ZnO nanoparticles for ethanol sensing, Current Applied Physics 8, 336-339 (2008).

[31] [J. Wang, C. Lee, Y. Chen, C. Chen, Y. Chen, C. Lin, Y. Chen, Double side electroluminescence from p-NiO/n$\mathrm{ZnO}$ nanowire heterojunctions, Applied Physics Letters 95, 131117 (2009). 
[32] N. Wu, M. Zhao, J.G. Zheng, C. Jiang, B. Myers, S. Li, M. Chyu, Porous CuO-ZnO nanocomposite for sensing electrode of high-temperature CO solid-state electrochemical sensor, S.X. Mao. Nanotechnology 16, 2878-2881 (2005). [33] X. Cai, Y. Cai, Y. Liu, S. Deng, Y. Wang, Y. Wang, I. Djerdj, Photocatalytic degradation properties of Ni(OH)2 nanosheets/ZnO nanorods composites for azo dyes under visible-light irradiation, Ceramics International 40, 57-65 (2014).

[34] Y. Zhao, X. Jia, G. Waterhouse, L. Wu, C. Tung, D. O’Hare, T. Zhang, Layered Double Hydroxide Nanostructured Photocatalysts for Renewable Energy Production, Advanced Energy Materials 6, 1501974 (2016).

[35] Adam, R. E., Pozina, G., Willander, M. and Nur, O., "Synthesis of ZnO nanoparticles by co-precipitation method for solar driven photodegradation of Congo red dye at different $\mathrm{pH}$," Photonics and Nanostructures - Fundamentals and Applications 32, 18 (2018).

[36] S. Elhag, K. Khun, V. Khranovskyy, X. Liu, M. Willander and O. Nur, Efficient donor impurities in ZnO nanorods by polyethylene glycol for enhanced optical and glutamate sensing properties, Sensors 16, 222 (2016).

[37] L. Zhou, W. Wang, and H. Xu, Controllable synthesis of three-dimensional well-defined BiVO4 mesocrystals via a facile additive-free aqueous strategy,Cryst. Growth Des. 8, 728 (2008).

[38] Elhag, S., Ibupoto, Z. H., Khranovskyy, V., Willander, M. and Nur, O., "Habit-modifying additives and their morphological consequences on photoluminescence and glucose sensing properties of $\mathrm{ZnO}$ nanostructures, grown via aqueous chemical synthesis," Vacuum 116, 26 (2015).

2525

[39] Etacheri, V., Roshan, R. and Kumar, V., "Mg-Doped ZnO Nanoparticles for Efficient Sunlight-Driven Photocatalysis,” ACS Applied Materials \& Interfaces 4(5), 2725 (2012).

[40] Hullavarad, S. S., Hullavarad, N. V., Pugel, D. E., Dhar, S., Venkatesan, T. and Vispute, R. D., "Structural and chemical analysis of pulsed laser deposited MgxZn1-xO hexagonal $(x=0.15,0.28)$ and cubic $(x=0.85)$ thin films," Optical Materials 30(6), 1000 (2008).

[41] Alnoor, H., Pozina, G., Khranovskyy, V., Liu, X., Iandolo, D., Willander, M. and Nur, O., "Influence of ZnO seed layer precursor molar ratio on the density of interface defects in low temperature aqueous chemically synthesized $\mathrm{ZnO}$ nanorods/GaN light-emitting diodes,” Journal of Applied Physics 119(16), 165702 (2016).

[42] Sakthivel, S., Neppolian, B., Shankar, M. V., Arabindoo, B., Palanichamy, M. and Murugesan, V., "Solar photocatalytic degradation of azo dye: comparison of photocatalytic efficiency of $\mathrm{ZnO}$ and $\mathrm{TiO}_{2}$," Solar Energy Materials and Solar Cells 77(1), 82 (2003).

[43] Selvam, N. C. S., Narayanan, S., Kennedy, L. J. and Vijaya, J. J., "Pure and Mg-doped self-assembled ZnO nanoparticles for the enhanced photocatalytic degradation of 4-chlorophenol," Journal of Environmental Sciences 25(10), 2167 (2013).

[44] Zhang, S., Liu, Z., Zhang, Y., Gao, S., Jin, R. and Wang, Q., "Highly effective photoelectrochemical performance of solar energy materials based on $\mathrm{Ag} 2 \mathrm{WO} 4-\mathrm{AgX}(\mathrm{X}=\mathrm{Cl}, \mathrm{Br}, \mathrm{I})$ sensitized $\mathrm{TiO}_{2}$ nanotube arrays," Ceramics International 44(6), 6665 (2018). 